\title{
Identification and determination of PAHs compounds in Anzali International Wetland
}

\author{
"F. Yazdanparast, A. Nouri and M. Rabbani
}

Department of Chemistry, Islamic Azad University, North Tehran Branch, Tehran, Iran

\begin{abstract}
The worst environmental pollutants in Anzali International Wetland are oily hydrocarbons especially aromatic and poly aromatic compounds (PAHs). The existence of oily compounds with approximate limit of concentration of $0.1 \mu \mathrm{g} / \mathrm{l}$ in aquatic environment bans the growth of fish larva and causes the generic state manner of animals. Anzali International Wetland, which is situated in the west - southern part of Caspian Sea where has environmental importance in life of living organisms and ecosystems. In this reseach, four sites, Pirbazar, Pasikhan, west and central parts, where are situated in Anzali International Wetland, have been studied in 2002. Waste sedimentation soil Sampling was performed during winter and spring in the above-mentioned regions. In the first stage, the purpose of sampling was to access optimum instrumental conditions and correct and precise procedures. Oily pollutants were extracted from water and it was done by using $\mathrm{CC1}_{4}$ solvent after cleaning and concentrating. The extracted samples were identified with gas chromatographic method with using polyaromatic standard solutions. By the powerful GC/MS method; results of qualitative analysis were confirmed. Also by GC/MS using SIM mode quantitative analysis were performed. Quantitative study of polyaromatic compounds has also been done by luminescence spectrophotometry. Some compounds which were identified in the water samples were: olifinic, aromatic and poly - aromatic compounds such as: antracene, fluourine, xylene, methylbenzene, naphthalene and acenaphtylene. Finally, the degree of biodegradation of compounds such as pristan $\left(\mathrm{C}_{19} \mathrm{H}_{40}\right)$ and phytan $\left(\mathrm{C}_{20} \mathrm{H}_{42}\right)$ in water samples was integrated.
\end{abstract}

Key words: Anzali International Wetland, Wetland pollutants, poly aromatic hydrocarbons, water pollution

*Corresponding Author, E-mail: Flora-yp@yahoo.com

\section{Introduction}

Lots of problems have been caused in recent decades by mismanagement in the protection of natural resources, such as Anzali International Wetland. Some of the most important factors which acceralate the pollution in this vital ecosystem are (Dabiri, 1996):

- Fast population growth.

- Increasing the amount of industries inside around sides of Anzali International Wetland incoming streams, industrial, agricultural and domestic sewerages, which flow to wetland without serious filtration and without continuous control of physicochemical parameters of its water.

- Air pollution, human activities, the flow of agricultural waste, discharges of solid waste and poisonous agricultural insecticides, heavy metals, petroleum and phenolic materials, nutrients in waste water, entering sediments of rivers to wetland with usage of sand and sludge for coal tars and agricultural fertilizers, phosphate recycling, mud and sand from sediments and pumping underground water are the main reasons to pollute Anzali International Wetland.

Wetland's characteristic has been changed during this recent century and it is simply caused by: entering of sewerages from Rasht City, accumulation of ground subsidence, increasing of sea level, thunder, flood, whirlpool, rain washing and biological activities of birds. The Caspian Sea level has been increased and it was therefore forced to enter the wetland, enhance the amount of chemicals, microbic and oily pollutants have also been increased. Wastewater with phosphate and organic nutrients provide ideal conditions for fish to increase, but if it carries substances such as: industrial wastewater, detergents, petroleum and painting materials and it will increase the mortality of species (Dabiri, 1996).

Industrial, agricultural and domestic wastewater with a great amount of organic and inorganic materials can cause decreasing of 
penetrating light and enhance oxygen dissolubility, photosynthesis decrease and variation in fish species occurs.

The study has been performed in Anzali International Wetland in 2002.

\section{Materials and Methods}

In order to study the pollutants of wetland's water, dark glass equipments should be used which had been cleaned out with $\mathrm{H}_{2} \mathrm{SO}_{4}$ $/ \mathrm{K}_{2} \mathrm{Cr}_{2} \mathrm{O}_{7}$ and distilled water. Sampling from specific stations was performed at random and transmitted to the glasses in order to extract the PAHs. Sampling was performed during winter and spring. Collecting samples in winter was only done to optimize the methods of sampling and to attain the correct statistical procedures. The main samples were therefore taken from four stations (Pirbazar, Pasikhan, west and central parts of the Wetland) in spring 2002.Extraction of non-polar organic pollutants of water is performed by use of nonpolar water miscible solvents such as: $\mathrm{N}$ hexane, dichloromethane, benzene, carbontetrachloride and toluene. In many cases use of mixture of solvents give better results in extraction but it can increase the interference of non-purity of solvents. One of the methods to extract oily materials is carbon tetrachloride and the other possible way in fluorescence method is using n-hexane and cyclohexane as extractor solvents because they can extract easily and have little toxicity (ASTM, 1997). In GC method oily hydrocarbons can be analyzed with SE-30, OV-73, OV-1 columns and mixture of oily aliphatic and polyaromatic can be analyzed with more polar columns eg. SE-52, SE-34, DB-2 and CP sil8 (Mutelet, et al, 2003). Chrompack Company had been used in order to measure wetland's PAHs. This method can be conducted in temperature range of $50-300^{0 \mathrm{c}}$. The polyaromatic compounds with more rings become heavier and so they will have high boiling point and solubility in aqueous media. (Dianh, et al., 1998) After entering water they get absorbed by suspending particles and precipated at the bottom of water ecosystem, so the samples from surface of water consist of lighter PAHs (Anonymous, 2001). In order to perform the qualitative and quantitative analysis, standard solutions must be used. So n-alkane and polyaromatic standard solutions were needed in the process. With comparison of standard solution's spectrums, oily hydrocarbons will beidentified.
The ASTM D3228-90 method has studied the oily hydrocarbons with GC. In this method the great part of light PAHs will be destroyed because of volatilization and oxidation, when they enter to the aqueous media. Studying the spectrum of these compounds need specific techniques. One of them is applying GC method with FID detector and comparing the spectrums of standard and real samples solutions. Another reliable method in this analysis is GC/MS method especially in identifying and measuring isomers. The other technique to determine the organic pollutants of water is HPLC especially in separation, qualitative and quantitative analysis of heavy compounds (poly - aromatics) by using C18 column and gradient washing method (Grop, 2000). The 4651-87 method can analyze polyaromatic hydrocarbons with HPLC. Therefore if an efficient HPLC would be in access, it can selectively analyze $\mathrm{PAH}, \mathrm{s}$ and heavy oily compounds specifically (Schoemakers, et al., 2000). Also the fluorescence method can be applied to study bicyclic aromatic compounds. This method is sensitive to polycyclic compounds and nonsensitive to aliphatic and non-fluorescent hydrocarbons. Irradiation of UV with specific wavelength causes the potential electronic levels of compounds to get excited and when multiplicity does not change with electromagnetic radiation, specific fluorescence radiation will be radiated. The frequency of such light could be calculated with the difference of electronic levels and excited levels. In luminescence spectrometer LS-5 perkin- Elmer the sample was put in a 1 $\mathrm{cm}$ quartz cell. The scanning procedure is between $\lambda_{e x}=310_{\mathrm{nm}} \quad \lambda_{e x}=330-450 \mathrm{~nm}$. The standard method is directly related to concentration versus intensity, so it is used for the quantitative analysis. When the origin of fluorescent material in water is known it can be used as a reference. In most cases the origin is unknown and is based on experimental experiences. Materials with boiling point less than $180^{\circ \mathrm{c}}$, which is separated from distillation of crude oil, can be used as a reference.

\section{Results}

The results of study of luminescence spectrum of real samples based on classification by PAHs are shown in Table 1 . 
Table 1: PAH rate of different water types

\begin{tabular}{|ll|}
\hline \multicolumn{1}{|c|}{ Water type } & \multicolumn{1}{c|}{ PAH rate } \\
\hline Underground & $10-50 \mathrm{ng} / \mathrm{l}$ \\
\hline Polluted & $20-250 \mathrm{ng} / \mathrm{l}$ \\
\hline Highly polluted & below $1000 \mathrm{ng} / \mathrm{l}$ \\
\hline Wastewater & below $100.000 \mathrm{ng} / \mathrm{l}$ \\
\hline
\end{tabular}

The fluorescence spectrophotometric results in the above case are shown in Table 2.

Table 2: Fluorescence spectrophotometric results of samples

\begin{tabular}{|lc|}
\hline Station & $\begin{array}{c}\text { Fluorescence } \\
\text { spectrophotometric } \\
\text { results (ng/l) }\end{array}$ \\
\hline Pirbazar & 110 \\
\hline Pasikhan & 19 \\
\hline Western Wetland & 25 \\
\hline Central Wetland & 216 \\
\hline
\end{tabular}

The GC/MS method approved the existence of aliphatic and aromatic hydrocarbons in Pirbazar and Pasikhan stations (Figures 1 and 2). Also samples from west and central parts of Wetland were polluted due to PAHs as shown in Figures 3 and 4 . When petroleum hydrocarbons enter the aquatic environments microbiological variations occur.
Normal chain hydrocarbons will change faster than branched isomers and cyclics.

The variations of biochemical petroleum compounds will be calculated by the ratio of normal hydrocarbons to isopropionides. The area of its peak is shown in Table 3.

Table 3: The degree of biodegration of pristan and phytane

\begin{tabular}{|lcc|}
\hline \multicolumn{1}{|c}{ Station } & $\mathrm{C}_{19} /$ Pristan & $\mathrm{C}_{20} /$ phytane \\
\hline Pribazar & 5.29 & 4.88 \\
\hline Pasikhan & 9.20 & 3.01 \\
\hline Western Wetland & 3.44 & 4.37 \\
\hline Central Wetland & 4.37 & 4.50 \\
\hline
\end{tabular}

In all stations the results of samples indicate the extraction time and convenient analysis are acceptable and the batteries are not allowed to affect the samples.

\section{Discussion and Conclusion}

Wetlands, especially Anzali International Wetland with its unique specifications, need more appreciation. Wetland contains values in different aspect of social, artistic, economics, and as cultural heritage needs cooperation for their protection.

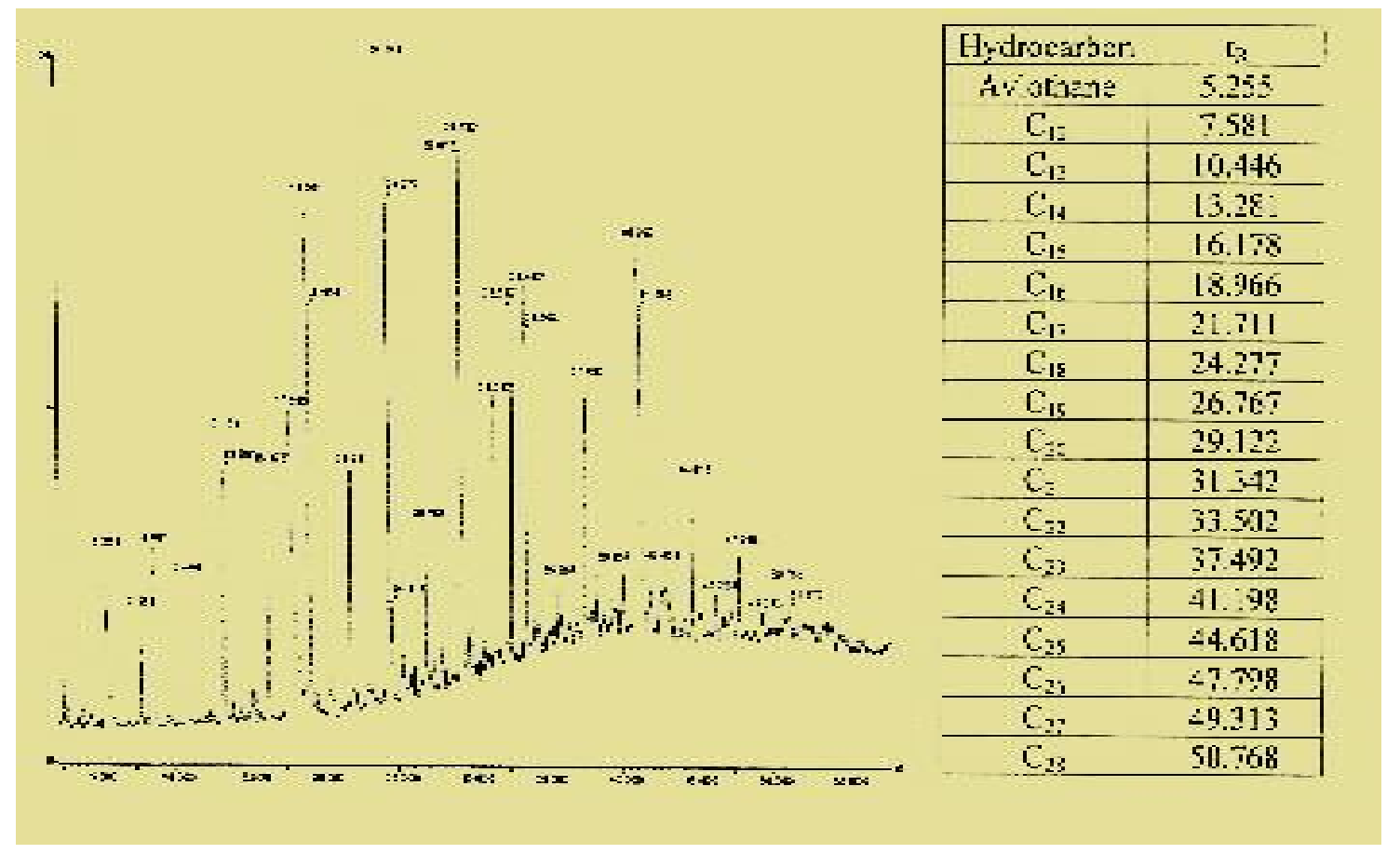

Figure 1: Determination of aliphatic and aromatic hydrocrbones by GC/MS methods in Pirbazar Station 


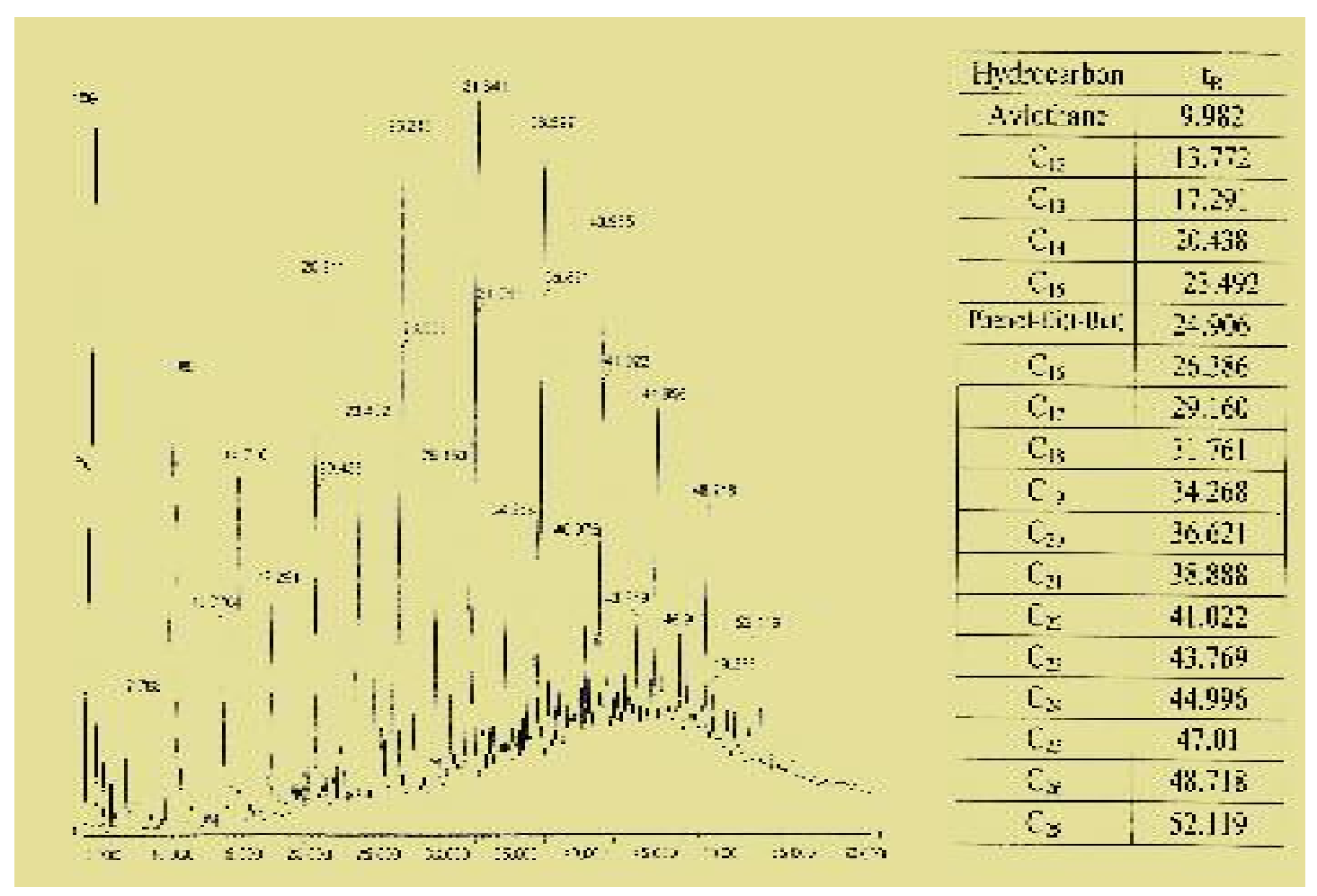

Figure 2: Determination of aliphatic and aromatic hydrocarbons by GC/MS method in Pasikhan Station

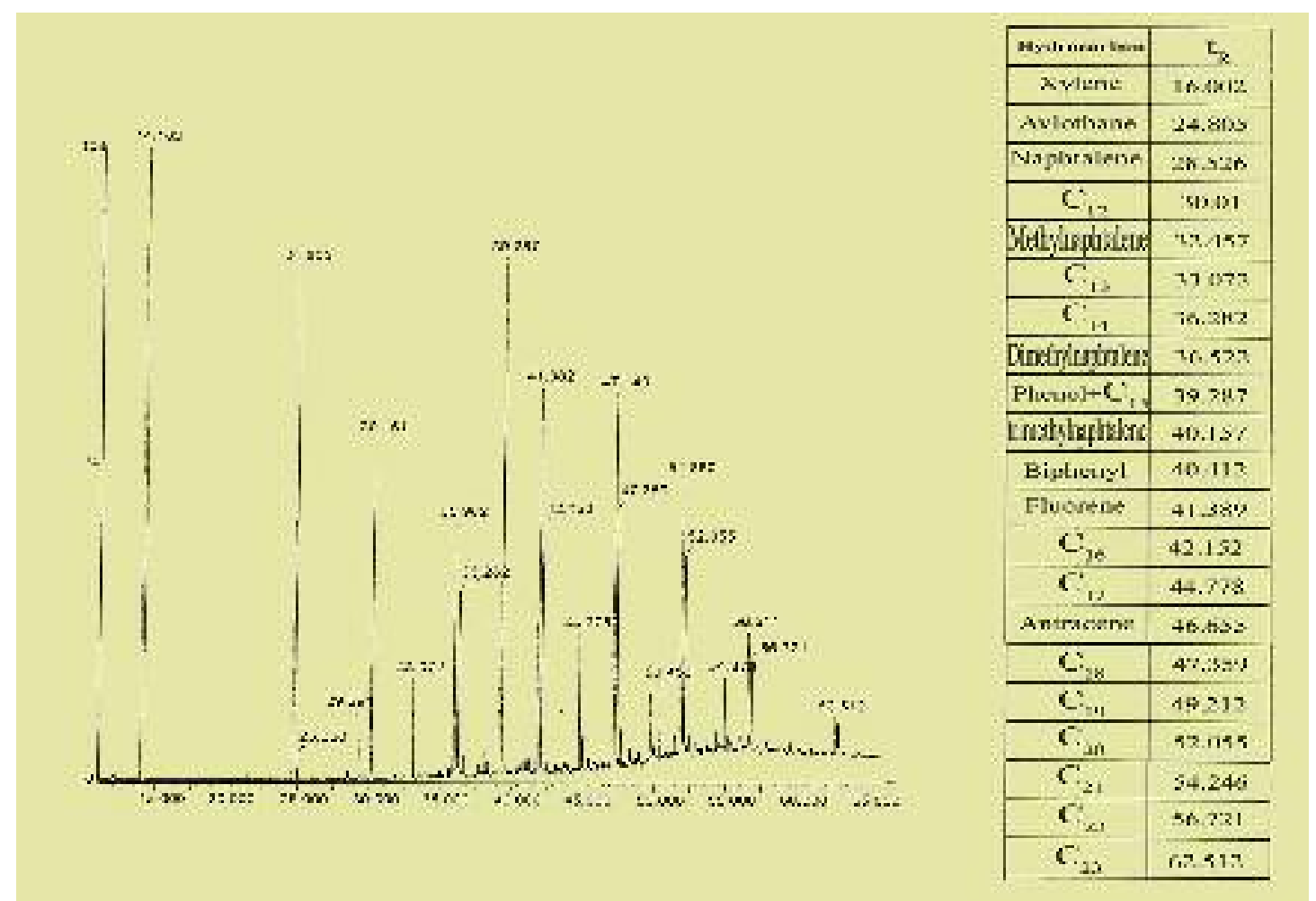

Figure 3: Determination of aliphatic and aromatic hydrocrbons by GC/MS methods in the west of Wetland 


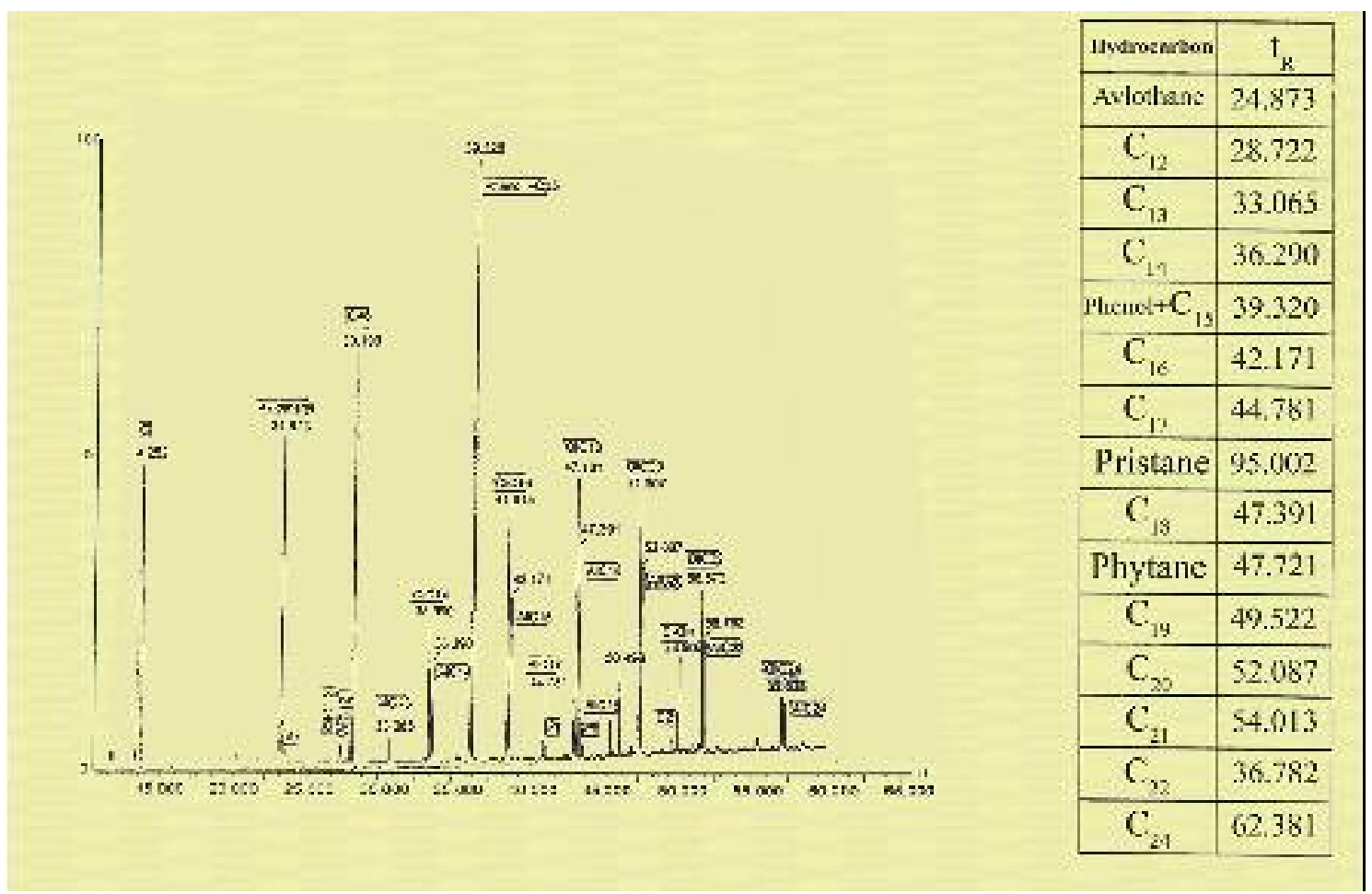

Figure 4: Determination of aliphatic and aromatic hydrocrbons by GC/MS methods in the center of Wetland

A great part of petroleum hydrocarbons with gasoline source and lubricating oils, toxic aromatic and non aromatic compounds, such as naphthalene, methyl naphthalene, dimethyl naphthalene, trimethyl naphthalene, antracene, acenaphtylene, fluorine, pyren, alkyl benzenes, xylene, biphenyls and... were identified in the Wetland's water. By using GC/MS method, aliphatic and aromatic hydrocarbons in Pirbazar and Pasikhan stations were identified and determined. The samples were polluted due to polycyclic hydrocarbons such as phenol-Di (t-But) and so on. Study of the samples in the west and central Wetland also confirmed the existence of xylene, naphthalene, methylnaphthalene, dimethyl naphthalene, phenol, trimethyl naphthalene, biphenyl, antracene, fluorine, pristan and phytane in water. The central zone of Wetland also was polluted and the other parts due to containing saturated aliphatic and aromatic oily hydrocarbons have high toxic index. Traces of some amounts of naphthalene in samples were observed. To attain this purpose, the retention time and mass spectrum of standards and samples have been identified.

\section{References}

Annual book of ASTM standards, 11.02, D3086-8, 1997

Anonymous, Gas chromatograghy, Miscellaneous. Journal of Chromatography, 940, (2): 165-186, 2001

Dabiri, M., Environmental pollution, Ettehad Publication, Tehran, 1996

Dinh, T., J. Fetzer and A. D. Compiglia, Monitoring and characterization of polyaromatic compounds in the environment. Talanta, 47, (4): 943-969, 1998

Grop, K., Efficiency through combining highperformance liquid chromatography and high reduction gas chromatography progress 1995 1999. Journal of Chromatography, 892, (1-2): 407-420, 2000

Mutelet, F. and M. Rogalsk, Using temerature radient gas chromatoghraphy to determine or predict vapor pressures and linear solvation energy relationship parameters of highly boiling organic compounds. Jouranl of Chromatography, 988, $(1,21): 117-126,2003$

Schoemakers, P. J., L. M. Jeroen, M. Oomen, J. Blomberg, W. Genuit, G. V. Velzer, Comparision of Comprehensive two-dimentional gas chromatography and gas chromatoghraphy mass spectrometry for characterization of cmplex hydrocarbon mixtures. Journal of Chromatography, 892, (1-2): 29-46 2000 
